\title{
A Transparência Administrativa e Comunicação Pública: análise do caso "funcionários-fantasmas" da Assembleia Legislativa do Maranhão
}

\author{
GOVERNMENT TRANSPARENCY AND PUBLIC COMMUNICATION: ANALYSIS OF THE "GHOST EMPLOYEES" \\ CASE IN THE LEGISLATIVE ASSEMBLY OF MARANHÃO, SÃO LUÍS, BRAZIL
}

\section{Asmynne Bárbara Barbosa dos Santos}

Mestranda do Programa de Pós-Graduação em Cultura e Sociedade (PGCULT) da Universidade Federal do Maranhão (UFMA). Graduada em Comunicação Social - Jornalismo pela UFMA e em Letras pela Universidade Estadual do Maranhão (UEMA).

E-mail: asmynne@gmail.com

\section{José Ferreira Júnior}

Professor do Programa de Pós-Graduação em Cultura e Sociedade (PGCULT) da Universidade Federal do Maranhão (UFMA). Doutor em comunicação pela Pontifícia Universidade Católica de São Paulo (PUC/SP) com pós-doutorado em Literatura Brasileira pela Faculdade de Filosofia, Letras e Ciências Humanas (FFLCH) da Universidade de São Paulo (USP).

E-mail: jferr@uol.com.br

Recebido em 23 de janeiro de 2017. Aprovado em 2 de maio de 2017.

\section{Resumo}

Este artigo analisa a comunicação pública na efetivação do direito à informação, mediante a utilização de ferramentas digitais do portal da transparência, abordando os prejuízos que a ausência desse direito gera para a sociedade. A abordagem teórica tem respaldo, entre outros autores, em Zémor, Matos, Bresser-Pereira. Foi utilizada metodologia qualitativa no estudo de caso sobre a reação da Assembleia Legislativa do Maranhão (ALEMA) diante da questão dos "funcionários-fantasmas". A análise constatou que o portal da transparência da ALEMA não usa ferramentas de comunicação pública.

Palavras-chave: Direito à informação. Interesse público. Comunicação pública. 


\section{Abstract}

This article analyzes the role of public communication in supporting the right to information, through the use of digital tools on the Transparency Portal, addressing the damages that the absence of this right generates for society. The theoretical approach is based on, among other authors, Zémor, Matos, BresserPereira. A qualitative methodology was used in the case study on the reaction of the Legislative Assembly of Maranhão (ALEMA) concerning the ghost employees" issue. The analysis found that the ALEMA transparency portal does not use public communication tools.

Keywords: Right to information. Public interest. Public communication.

\section{Introdução}

O incentivo à transparência das informações públicas deve ser um dos objetivos centrais dos órgãos da Administração Pública. Entende-se que a ampla divulgação da execução orçamentária e de outros dados sob a guarda do poder público não só condiz com os preceitos da moderna Administração Pública, mas é fundamental para o exercício pleno da cidadania e fortalecimento da democracia participativa. Dessa forma, a criação dos Portais da Transparência constitui um espaço de atuação da comunicação pública.

Para Zémor (1995), o poder público civilizado acumula dados e decisões que afetam a vida em sociedade e cabe ao serviço público tornar as informações conhecidas.O acesso à informação é um forte mecanismo de controle e participação social. Contudo, a falta de transparência ocasiona corrupção, quebra da legitimidade do órgão público e distancia o cidadão da Administração Pública.

Este estudo tem por objetivo analisar a comunicação pública no portal da transparência da Assembleia Legislativa do Maranhão (ALEMA), para investigar a formação de uma esfera pública interconectada. O ponto central de investigação baseia-se na repercussão do caso dos "funcionários-fantasmas" e a ausência de informações exigidas pela Lei de Acesso à Informação no portal.

Discute-se também o papel da comunicação pública na promoção da transparência administrativa. A partir do desenvolvimento da administração pública, esses conceitos comunicação pública e direito à informação - são examinados por serem essenciais à cidadania.

Por último, procede-se ao estudo de caso da ALEMA com o intuito de demonstrar os efeitos positivos e os prejuízos da ausência da transparência pública. 
Parte-se da premissa de que a ausência de transparência é prejudicial à construção da cidadania, sendo que o cumprimento formal da lei traz benefícios para os cidadãos. A metodologia aplicada é de caráter qualitativo e tem por instrumento o estudo de caso. A escolha se justifica pelo fato de, no estudo de caso, ser viável a realização de pesquisas que investiguem um fenômeno contemporâneo dentro de seu contexto real (YIN, 2001). Realizou-se uma observação estruturada do portal da transparência para verificar seus objetivos e seu funcionamento entre os meses de julho e dezembro de 2016 com o propósito de mapear os usos da comunicação pública e o cumprimento da Lei de Transparência. Este estudo de caso se baseou em uma pesquisa bibliográfica e documental, necessária para a formação do arcabouço teórico que fundamenta a observação estruturada do portal. Para Ludke e André (1986), a observação é um dos instrumentos básicos para coleta dados na investigação. É uma técnica que utiliza um percurso, previamente desenhado, de forma a obter informação de determinado aspecto da realidade.

A temática deste artigo se justifica por estar em consonância com o crescente interesse da sociedade civil pela participação ativa na gestão pública. Esse anseio encontra respaldo no direito à informação, que é base do conhecimento necessário para a atuação cidadã. O debate deste tema é importante para compreender a comunicação pública como elemento para a governança pública.

\section{A relação entre o público e o privado na administração brasileira}

No Brasil, a Administração Pública passou por três modelos administrativos - a administração patrimonialista, a administração burocrática e a administração gerencial que consolidaram procedimentos e ferramentas que afastavam ou aproximavam a participação popular. A principal característica da Administração Pública, quando analisada pelo viés histórico, é evoluir e aprimorar os modelos de gestão que são classificados de acordo com a maneira que a coisa pública é gerida. Dessa forma, o modelo administrativo mais moderno enfatiza a participação social, a transparência e a comunicação com o cidadão. Paralelo à evolução da Administração Pública brasileira, encontra-se a Comunicação Pública - ainda em fase de construção conceitual por estudiosos como Brandão (2009), Matos (2009), Oliveira (2004) e outros - que tem no seu arcabouço teórico a ênfase, como esclarece Monteiro (2009), no diálogo do Estado com a sociedade e o direito à informação como base do exercício da cidadania. Neste tópico, analisa-se o patrimonialismo na gestão brasileira com a intenção de perceber como o Estado comunica-se com o cidadão e permite a participação social. 
A Administração Pública brasileira tem suas raízes no patrimonialismo, pois a consolidação do Estado patrimonial português e sua lógica estamental governaram a dinâmica colonial. O termo patrimonialismo denota a incapacidade ou a relutância do príncipe distinguir entre patrimônio público e seus bens privados" (PEREIRA, 2010, p. 35). Na fase patrimonialista, que perdurou de 1500 até 1930, Silva (2013) explica que os governantes consideravam o Estado como seu patrimônio, não havendo distinção entre o público e o privado, e essa permeabilidade tem como principais consequências a corrupção e o nepotismo, marcas da administração pública brasileira.

Atualmente, um patrimonialismo "discreto" ainda existe nos órgãos públicos, coexistindo com os modelos burocrático e gerencial. Essa coexistência encontra respaldo na discricionariedade administrativa, utilizada ou interpretada inadequadamente por maus gestores para obtenção de vantagens pessoais, nepotismo e corrupção. Apesar de ser um modelo de administração típico dos Estados absolutistas europeus, ainda hoje encontra algumas derivações, como o patrimonialismo de viés político em que ocorre a "utilização dos cargos públicos eletivos ou executivos para o usufruto de vantagens econômicas através do uso dos recursos da coisa pública" (SORJ, 2006, p. 10).

Ao longo da história brasileira, houve uma interligação entre a ascensão dos direitos de cidadania e os instrumentos estatais para operacionalizá-los. A reforma administrativa, mais recente, e a opção pelo modelo gerencial também deixaram nítida a necessidade de transparência na gestão pública, culminando na aprovação de leis que compactuam com a transparência. Sacramento e Pinho (2007) observam que a transparência é um instrumento que pode contribuir para reduzir a corrupção no espaço público e expandir a democracia. Para Duarte (2009), a comunicação pública é um instrumento de interesse coletivo para fortalecer a cidadania e no setor público incorpora o pressuposto da transparência.

No Brasil, o termo "comunicação pública" passou a ser usado a partir da década de 1980 para denominar a comunicação estatal. Oliveira (2004) rememora que, com o fim da ditadura militar, o conceito passou a ser compreendido como sinônimo de convergência entre comunicação, democracia e cidadania, num cenário que envolve Estado, governos e entidades da sociedade civil. Dessa forma, compreende-se a comunicação pública a partir de uma perspectiva que tem a participação da sociedade civil e o livre exercício da cidadania na condição de elementos essenciais. Matos (2009) define a comunicação pública como "processo de comunicação instaurado em uma esfera pública que engloba Estado, governo e sociedade, um espaço de debate, negociação e tomada de decisões relativas à vida pública do país". 
A comunicação pública pressupõe funções. Zémor (1995) define com os seguintes parâmetros: a) informar, isto é, levar os assuntos ao conhecimento do público, prestar contas e valorizar as atividades estatais; b) ouvir as demandas, as expectativas, as interrogações do público, por meio dos serviços de ouvidoria; c) estimular e fortalecer o debate público e a participação política; d) contribuir para assegurar e fortalecer as relações sociais, estimulando o sentimento de pertencer ao coletivo e a tomada de consciência do cidadão enquanto ator social e político; e) acompanhar as mudanças, tanto as comportamentais quanto as da organização social; e f) alimentar o conhecimento cívico.

Sobre essas funções, o destaque, quando se relaciona comunicação pública e cidadania, é fornecer espaços de informação, como os portais da transparência. Dessa forma, o cidadão adquire um papel ativo, pois "ao mesmo tempo em que ele respeita e se submete à autoridade das instituições públicas, ele protesta sobre a falta de informação, ou sobre suas mensagens mal construídas, incompletas ou mal divulgadas" (BARROS; BERNARDES, 2011, p. 8-9).

Com as mudanças na administração pública, percebe-se que, no patrimonialismo, a comunicação não é vista como um elemento constituinte da cidadania, porque o gestor é o "dono" da informação. No entanto, alguns avanços acontecem, de modo pontual, com a burocracia, instância na qual o cidadão passa a ser visto como cliente, como receptor de um serviço. É oportuno observar que a comunidade internacional, por intermédio da Organização das Nações Unidas (ONU) e da Organização dos Estados Americanos (OEA), entende que seja efetivamente um direito humano o acesso à informação, como ressalta Rose Maria Vidal de Souza, em sua tese de doutorado:

O indivíduo, tendo acesso a informações do Estado do seu país, tende a fortalecer sua capacidade de participar de modo efetivo das decisões que o afeta. $\mathrm{O}$ acesso a documentos, arquivos e estatísticas, constitui-se em um dos fundamentos para a consolidação da democracia que possibilita a transparência dos atos públicos e busca pelas informações constituindo-se em uma forma de participação do povo. (SOUZA, 2016, p. 60)

\section{O portal da transparência como instrumento da Comunicação Pública}

A Comunicação Pública, para Escudero (2015), tem função primordial: atuar como mediadora entre o Estado e a sociedade civil, além de permitir a abertura de canais democráticos que viabilizem o livre fluxo de informações entre os atores que participam da esfera pública. Partindo dessa definição, empreende-se neste tópico uma 
discussão sobre a transparência administrativa e em seguida se atesta a importância da comunicação pública nos portais. Por fim, discute-se o papel da comunicação pública na esfera pública interconectada.

A transparência das informações públicas é um direito fundamental previsto na Constituição Federal (CF) de 1988 - no artigo $5^{\circ}$, inciso XXXIII, consagra o princípio do direito à informação ao postular que todos têm direito a receber dos órgãos públicos informações de interesse particular ou de interesse coletivo. $\mathrm{O}$ direito à informação encontra respaldo também no inciso II do parágrafo $3^{\circ}$, no artigo $37^{\circ}$, e no parágrafo $2^{\circ}$, do artigo $216^{\circ}$. O princípio da transparência não está explícito no texto constitucional - como os princípios da moralidade, publicidade e outros -, contudo é um dos mais importantes para harmonizar a relação do Estado com a sociedade. Em 2011, o Governo Federal instituiu a Lei 12.527, ou Lei de Acesso à Informação (LAI), que regula o acesso à informação pública e, posteriormente, a criação do portal da transparência (Decreto 5.482/2012).

A obrigatoriedade de expor em ambiente virtual as contas do Poder Público, denominada de transparência ativa, estende-se para os estados e municípios. Estão submetidos à LAI todos os órgãos públicos integrantes da administração direta dos Poderes Executivo, Legislativo, incluindo as Cortes de Contas, Judiciário e do Ministério Público, além das entidades controladas direta ou indiretamente pela União. Dessa forma, o órgão deve ter a iniciativa de divulgar, sem necessidade de ser solicitado diretamente, as informações de interesse geral ou coletivo. É ativa, pois parte da Administração Pública divulgar e expor para a sociedade, pois:

O direito de acesso à informação impõe duas obrigações sobre os governos. Primeiro, existe uma obrigação de publicar e disseminar informações essenciais sobre o que diferentes órgãos públicos estão fazendo. Segundo, os governos têm obrigação de receber do público pedidos de informação e respondê-los, disponibilizando os dados solicitados e permitindo que o público tenha acesso aos documentos originais indicados ou receba cópias dos mesmos (MARTINS; PAIVA, 2010, p. 234)

Na LAI diversos artigos fazem referência à transparência ativa; contudo, os artigos $3^{\circ}$, inciso II e $8^{\circ}$ expressam de forma clara esse princípio. $\mathrm{O}$ artigo $3^{\circ}$ preconiza a divulgação de informações de interesse público, independentemente de solicitações. Já o artigo $8^{\circ}$ esclarece que "é dever dos órgãos e entidades públicas promover, independentemente de requerimentos, a divulgação em local de fácil acesso, no âmbito de suas competências, de informações de interesse coletivo ou geral por elas produzidas ou custodiadas" (BRASIL, 2011). 
A transparência ativa também pressupõe uma seção específica de Acesso à Informação nos sites da Administração Pública, com o intuito de divulgar as informações. O objetivo é facilitar o acesso da sociedade: "O acesso atribuído à informação indicará se realmente há transparência. A dificuldade para obtenção do material, o excesso de etapas para se adquirir determinado relatório representa pontos negativos" (FIGUEIREDO; SANTOS, 2013, p. 20).

É importante destacar que essa nova legislação altera um paradigma até então presente na administração pública, tornando como regra a cultura da transparência e o segredo como exceção. Destaca-se que o não cumprimento do direito de informação não é só uma grave afronta às leis, mas um impedimento ao exercício da cidadania, pois, como esclarece Silva (1992), nenhum indivíduo pode estar no pleno gozo da cidadania se não tem acesso às informações de caráter público. Dessa forma:

O direito a receber informações verdadeiras é um direito de liberdade e caracteriza-se essencialmente por estar dirigido a todos os cidadãos, independentemente de raça, credo ou conviç̧ão político-filosófica, com a finalidade de fornecimento de subsídios para a formação de convicções relativas a assuntos públicos. (MORAES, 2000, p. 162)

De forma sucinta "a transparência pública é o movimento de prestação de contas de toda a administração pública e abertura de seus registros financeiros e de seus atos para fiscalização da sociedade em geral" (BATISTA, 2012, s/p). As consequências desse movimento, como postula Bresser-Pereira (1998), é que a transparência do Estado se efetiva pelo acesso do cidadão à informação governamental; e, com esse acesso, a relação entre Estado e sociedade se torna mais democrática. A transparência é, portanto, elemento crucial para a cidadania, e a comunicação pública é essencial para caracterizar esse processo, principalmente, no portal da transparência.

De todo esse arcabouço jurídico, destaca-se a criação do portal da transparência, ferramenta que possibilita não apenas a superação de uma cultura de sigilo, fundamentada nos entraves e resquícios da administração patrimonialista, mas que contribui para o efetivo exercício da cidadania, haja vista que, ao tornar transparentes as ações dos órgãos públicos, permite o controle social.

O objetivo do portal é "apoiar a boa e correta aplicação dos recursos públicos ao possibilitar o acompanhamento e fiscalização pela sociedade dos gastos públicos" (CGU, 2011, p. 11). Deve disponibilizar conteúdo de natureza informativa, com o objetivo de estimular a prática do controle social, funcionando como um espaço de comunicação e diálogo com o cidadão. 
O portal é um "site na internet que oferece grande variedade de serviços, tais como correio eletrônico, foros de discussão, dispositivos de busca, informações gerais" (NEIVA, 2013, p. 442). Dessa forma, não pode ser apenas um repositório de dados públicos; não basta o simples acesso, o cidadão precisa compreender as informações de forma didática, porque assim incentiva-se a participação nas decisões governamentais, o controle e a fiscalização dos gastos públicos, ou seja, o objetivo primordial das iniciativas de transparência.

O contexto democrático apenas se efetiva pela participação do povo nas deliberações. É necessário que haja liberdade de expressão e canais de comunicação que possibilitem a participação. O portal atua como ferramenta de comunicação pública, pois "a administração pública, em qualquer esfera, mais que a administração privada, precisa abrir portas e compartimentos, dando vazão à transparência e à correção de atitudes" (TORQUATO, 2008, p. 121).

Para entender o alcance dos portais como um espaço da esfera pública que utiliza Tecnologias da Comunicação e Informação (TICs), Yochai Benkler (2009) aborda o conceito de esfera pública interconectada, relacionando-a com as mudanças introduzidas pelas novas tecnologias na sociedade. Com a internet, a esfera pública, antes dominada pela mídia, passa para uma fase em que o cidadão não só recebe conteúdos, mas também os constrói, caracterizando, portanto, a esfera pública interconectada. Benkler (2009) esclarece que as TICs tiram o cidadão da passividade, tornando-os mais participantes e engajados no debate. Nesse novo espaço qualquer um pode "falar", inquirir e investigar. Britto (2006) corrobora esse posicionamento ao afirmar que, com a popularização das novas tecnologias, torna-se possível maior aproximação do ideal democrático do acesso às informações com transparência, solidariedade, direitos humanos e participação dos cidadãos.

É cabível a atuação dos instrumentos de comunicação pública na esfera pública interconectada. Um dos objetivos da comunicação pública é "a discussão de temas de interesse comum a serem debatidos na esfera pública e o seu resultado é a formação da opinião pública e o fortalecimento da cidadania" (ESCUDERO, 2015, p. 112). E, como afirma Brandão, a comunicação pública também se identifica com a Comunicação do Estado e/ou Governamental e mostra-se como a "dimensão da Comunicação Pública que entende ser de responsabilidade do Estado e do Governo estabelecer um fluxo informativo e comunicativo com seus cidadãos" (BRANDÃO, 2009, p. 5). Assim, a comunicação atua na esfera pública interconectada a partir de sua posição estratégica para a tomada de decisão, além da capacidade de dar sentido às informações e dados.

Torquato (2008) compreende que a comunicação pública tem como uma de suas funções conceder o direito à informação como base da cidadania. Assim, o portal da 
transparência, como ferramenta de promoção desse direito, também realiza o ideal da comunicação pública, que consiste em informar e comunicar, levando-se em conta a formação da opinião pública e atuação do cidadão na esfera pública. Isso se realiza quando a comunicação pública atua para atender melhor o cidadão, de forma a trazê-lo para a esfera pública (FERREIRA, 2009), acompanhando o desenvolvimento da sociedade para melhor.

Quando a Administração Pública não cumpre a lei, ocorre uma quebra da legitimidade do espaço público, ocasionando ruptura do pressuposto fundamental do portal da transparência, que é estabelecer o diálogo e a participação com base na informação.

\section{O caso dos funcionários-fantasmas na ALEMA}

O ato número 349 publicado no Diário Oficial do Estado do Maranhão em 12 de maio de 2016 exonerou a servidora Lilian Dias Alves do cargo de diretora administrativa da Assembleia Legislativa do Estado (ALEMA). De acordo com o Sindicato dos servidores da Assembleia Legislativa do Maranhão (SINDSALEM), a servidora recebia remuneração de 18 mil por mês, sem trabalhar. A exoneração ocorreu a partir de denúncias feitas por organizações da sociedade civil e Ministério Público do Estado de que Lilian faria parte do total de 200 funcionários-fantasmas da Assembleia. A conjuntura que permitiu o escrutínio da sociedade nos atos públicos e posterior pressão social para os devidos ajustes legais começou a ser desenhada com a Constituição Federal de 1988 e, posteriormente, em 2011, com a regulamentação do acesso à informação, como explicado no item anterior.

No Maranhão, constata-se que a implementação da LAI não ocorreu no mesmo ritmo em todos os poderes, o que demonstra a persistência de uma cultura paternalista e mentalidade de favorecimento pessoal na Administração Pública. De iniciativa do Poder Executivo, o projeto de lei que criou o portal da transparência da ALEMA, disponibilizando o acesso públicos aos atos administrativos do governo, remonta a 2009. Contudo, desde a implementação, o portal apresenta falhas no cumprimento do disposto na LAI.

A ALEMA apresenta problemas na aplicação da transparência. Um dos casos mais notórios está relacionado à denúncia de que a assembleia teria "funcionários-fantasmas" lotados em gabinetes de deputados estaduais e em outros setores administrativos. De acordo com o SINDSALEM, a folha de pagamentos da casa legislativa maranhense passa de R \$250 milhões por ano. Já no portal da transparência não existia, até novembro de 2016, dados recentes com nomes e quantidade de funcionários, nem os salários recebidos por eles. Para Matos (2009), o "funcionário-fantasma” é 
Aquela pessoa nomeada para um cargo público que jamais desempenha as atribuições que the cabem. Ou seja, recebe sem trabalhar, se enriquece ilicitamente à custa do erário e do suor do contribuinte, na maioria das vezes com remunerações superiores a da maioria da população brasileira. Trata-se de experiência corriqueira no Estado brasileiro totalmente reprovável, tanto do ponto de vista da autoridade que nomeia quanto da pessoa que aceita ser favorecida por tal ilicitude (MATOS, 2009, s/p).

Em resposta a essa situação, o Ministério Público do Estado do Maranhão (MPMA) ajuizou a ação civil pública (nº 0819616-13 2016, 8.10.0001) através da Vara de Interesses Difusos e Coletivos com o intuito de requerer da ALEMA a divulgação de informações de interesse público. O MP alega que o portal não cumpre sua função, pois não dispõe de informações completas sobre as atividades desenvolvidas pelo órgão, envolvendo o manuseio de recursos públicos.

Diante desse cenário em que a lei não é cumprida, vale destacar que, na análise de Ferreira (1993), a máquina administrativa do Estado está tomada por resquícios do patrimonialismo, sendo que a vontade do administrador se sobrepõe ao interesse público: "Quem tem qualquer parcela de poder se imagina um 'coronel', estabelece o favor discricionário e, sempre que pode, impede o direito" (FERREIRA, 1993, p. 207). Ao ditar o que o cidadão pode ou não saber, o gestor ultrapassa seu poder discricionário. Para Bertazzi (2011, p. 26), "o cidadão e a sociedade civil ficam, portanto, a depender da discricionariedade burocrática, situação perniciosa para a construção de uma administração pública transparente".

Os “funcionários-fantasmas" da ALEMA ocupavam cargos de confiança. De acordo com Tabatcheik (2015), o sistema de uso de cargos em comissão pode estar relacionado a fins políticos e econômicos de interesse privado, subvertendo a lógica de bom uso do dinheiro público.

O primeiro tipo está destinado para "o sistema político, ou seja, o aparelhamento das lideranças locais pelos deputados estaduais para a criação e manutenção de suas bases eleitorais" (TABATCHEIK, 2015, p. 215). O esquema inicia com empréstimo de cargos em comissão por deputados - quem possui mais cotas para os que possuem menos. Dessa forma, o dinheiro público é utilizado para se fazer atividade política de interesse privado do parlamentar, além de estabelecer uma rede de influências. O segundo tipo tem viés econômico e o objetivo de arrecadar dinheiro encontrando pessoas confiáveis que devolvam os salários recebidos para os parlamentares, o que constitui crime. E o terceiro tipo ocorre com a montagem de uma "caixinha de campanha" pelos comissionados escolhido por indicação parlamentar. 
Cabe ressaltar que o legislativo é órgão de representação popular e recebe o nome de Casa do Povo. Tem por função, além de representar a população, legislar e fiscalizar a aplicação de recursos públicos. Contudo, para que a ALEMA cumprisse a LAI, foi necessária intervenção do Ministério Público que classificou o atual modelo do Portal da Transparência do órgão legislativo como inadequado, pois não revela informações completas de como os recursos foram gastos e não fornece, em relação aos servidores, o nome e salário recebido. Na consulta realizada no portal, dia 15 de setembro de 2016, às 16h43, percebe-se que no item "Despesas com pessoal" há apenas valores gerais do que foi gasto, sem detalhamento. Contudo, em cumprimento à ação civil do MP, a ALEMA divulgou no dia 27 de julho, às 18h, a relação com o número total de funcionários, mas não traz o cargo nem o local de trabalho, como exige a LAI. Outro destaque é que a lista não foi disponibilizada no portal. Ou seja, a falta de transparência é notória e cria ambiente propício para corrupção.

A demanda por transparência faz sentido quando se consegue, através dela, evitar o abuso do poder político por parte das autoridades, permitir o escrutínio público e o constrangimento àqueles que fazem, por exemplo, mau uso do dinheiro público e do poder, utilizando-se dos meandros da política, das lacunas existentes no nosso sistema democrático, para o exercício de atividades antirrepublicanas, como o tráfico de influência, a corrupção, dentre tantas outras. (ALMADA, 2016, s/p)

Assim, não se admite em um Estado Democrático de Direito, no qual o poder é exercido em nome do povo, que este fique privado das informações quanto à gestão da coisa pública. Portanto, para efetivar o princípio democrático da transparência na Administração Pública, é imprescindível o direito à informação sobre as atividades administrativas. A atuação do MP, como órgão de controle, de acordo com o secretário-geral da ONG Contas Abertas, Gil Castello Branco, não têm como "enfrentar a corrupção na exata proporção em que ela acontece" (GARCIA, 2008, s/p), sobretudo pelo fato de o Brasil ser um país de dimensões continentais. Afirma ainda que, se a sociedade civil organizada tivesse acesso a todas as informações do poder público, as chances de manter o devido controle sobre os gastos governamentais seriam muito maiores.

A existência de funcionários-fantasmas é perpetuada num cenário de ausência de transparência. Como se percebe no caso da ALEMA, todos os funcionários foram nomeados pela mesa diretora e com as respectivas portarias publicadas em Diário Oficiais. Contudo, esse instrumento é de circulação mínima e não chega efetivamente às mãos da população. A lei da transparência é clara ao exigir um portal específico para a divulgação de informações de interesse público. 


\section{Perspectivada Comunicação Pública no portal da transparência da ALEMA}

Para a análise do portal da transparência da ALEMA, foi observada a presença de ferramentas de comunicação pública, além de canais de participação e qualidade da informação. A intenção foi investigar de que forma o portal da transparência da assembleia utiliza instrumentos de comunicação pública e se isso inibiria casos como o dos "funcionários-fantasmas". Para tanto foi aplicado um questionário de observação estruturada do portal, no período entre julho e dezembro de 2016. A seguir são expostos os itens observados e a respectiva análise.

Primeiramente, observa-se o contexto. O portal da transparência está alocado no site institucional da assembleia, possui atualização diária e deste a ação civil pública proposta pelo MP-MA sofreu alterações, no ano de 2016, com o intuito de adequar o portal ao que dispõe a LAI. O atual portal disponibiliza dados a partir do mês de outubro. Para acessar informações de datas anteriores - o que engloba o período de denúncia dos “funcionários-fantasmas" - é necessário acessar o portal anterior. Também é importante destacar que o banco de dados do portal é uma extensão do portal da transparência do Governo do Estado do Maranhão. Assim, a ALEMA não tem um setor responsável pela administração da transparência.

O próximo item analisado corresponde ao acesso ao portal. Na página inicial do site institucional encontra-se uma aba com links para as principais informações sobre a Casa Legislativa. O link para o portal é o último e, ao clicá-lo, o usuário é direcionado para outra página. Não há banners na página principal que destaquem o acesso ao portal.

O segundo item observado investiga se o portal disponibiliza respostas às perguntas mais frequentes da sociedade. O portal tem esse item, mas as perguntas estão limitadas a esclarecer as especificidades do trabalho legislativo. Não há orientações sobre a legislação da transparência, quais as informações encontradas ou como o usuário pode proceder caso não encontre algum dado no portal.

O terceiro item observado analisa se o portal disponibiliza tutoriais para melhor uso dos recursos do site. O tutorial é uma importante estratégia de comunicação pública, haja vista que auxilia o cidadão no uso eficiente das informações públicas; contudo, tal item não foi encontrado no portal da ALEMA.

O quarto item analisado investiga se o portal publica anualmente relatório estatístico informando sobre a quantidade de pedidos de informação recebidos, atendidos e indeferidos, bem como informações genéricas sobre os solicitantes (idade, nível de escolaridade e outros). Esse documento é importante por ser uma forma de prestar contas

$114 \frac{\text { Comunicação \& Inovação, PPGCOM/USCS }}{\text { v. 18, n. } 37 \text { (103-118) maio-ago } 2017}$ 
para a sociedade sobre como, por quem e a frequência com que o portal da transparência é utilizado. Além desse aspecto, informações de mesma natureza também podem auxiliar pautas para os veículos de comunicação. Contudo, na ALEMA essas informações não são públicas, pois o relatório não é publicado.

O quinto item analisa aspectos de facilidade de acesso: se a página contém ferramentas de busca que permitam o acesso à informação de forma objetiva, clara e transparente e em linguagem de fácil compreensão. Ainda nesse item foi observado se o portal possui glossário com os termos mais frequentes e sua explicação em linguagem acessível. Entende-se que o portal é um instrumento de comunicação pública e de formação da esfera pública de debates, considerando-se que a LAI ressalta o teor comunicativo e de promoção do interesse público a partir da disponibilização das informações. Portanto, o portal deve incluir espaços que orientem o cidadão para que navegue de forma intuitiva e compreenda o que está sendo divulgado. Os portais são páginas na internet que funcionam como ponto de acesso direto a um conjunto de serviços e informações. Contudo, tais itens não foram encontrados no portal da ALEMA. A informação precisa da comunicação pública para ter utilidade social e, assim, concretizado outros direitos. A simples disponibilização de dados, sem compreensão, não melhora a comunicação com a sociedade.

O sexto item investiga se a página permite a gravação de informações disponibilizadas em formatos eletrônicos abertos que facilitem a análise, como planilhas e texto. Todas as informações do portal podem ser baixadas em PDF e apenas dados como diárias estão disponíveis em Word e Excel. Com essa, limitação, jornalistas interessados na coleta de dados, e outros profissionais em geral, têm mais dificuldades de analisar dados, acessá-los livremente e compartilhá-los. O formato de dados abertos também permite, por exemplo, que as informações sejam transformadas em infográficos, o que auxiliam sua compreensão, e sirvam também de banco de dados para aplicativos que aproximem a informação do cidadão.

O sétimo item analisado busca encontrar outra ferramenta importante de comunicação do órgão com a sociedade o "Fale Conosco", um link para o cidadão encaminhar perguntas, dúvidas e sugestões para o órgão. O portal da ALEMA não possui essa simples ferramenta, o que demonstra ainda mais o caráter de opacidade com que a assembleia reveste as informações de interesse público.

A carência de mecanismos de comunicação pública é ainda mais agravante em um estado cuja população tem pouco acesso à internet (de acordo com dados do IBGE de $2015,80,4 \%$ dos lares maranhenses não têm acesso à rede mundial), aliado a um cenário de exclusão digital que está também relação ao uso e entendimento das informações 
disponibilizadas pelo portal. A comunicação pública se mostra como um guia para que o cidadão compreenda efetivamente os dados, os números e siglas que envolvem a administração pública. Sua ausência no portal evidencia uma falha que enfraquece a própria noção de democracia e cidadania.

\section{Considerações finais}

O movimento pela transparência dos atos e das contas públicas é um dos itens fundamentais para a boa governança. A gestão da transparência e o acesso à informação parte do pressuposto de que o amplo e o irrestrito conhecimento dos gastos e ações da administração é um meio poderoso de combater práticas de mau uso do dinheiro público. Dessa forma, a presença da comunicação pública nos portais é necessária para que o cidadão possa discutir questões e formar opinião nesse espaço.

O descumprimento da LAI revela um quadro de resquícios do patrimonialismo na administração, pois a falta de transparência sinaliza quebra das expectativas do que a sociedade considera como comportamento ideal e íntegro dos detentores de cargos públicos. Em contrapartida, o atendimento à lei e abertura dos dados públicos para escrutínio do cidadão configura cenário ideal de uma administração responsável.

Quando a sociedade tem acesso, por exemplo, aos gastos públicos, a transparência cumpre um importante papel: a responsabilização. Sabendo como o gestor aplica os recursos, o cidadão tem a quem responsabilizar em caso de mau uso. Outra questão relevante está relacionada ao acesso à informação. Se há dificuldade de acesso ou se o Poder Judiciário precisa ser acionado para que o órgão cumpra a lei, percebem-se pontos negativos. Em relação aos empecilhos para o acesso, entra em cena a comunicação pública, que pode e deve ser acionada para configurar esses portais em espaços de diálogo com o cidadão.

O direito à informação não contempla apenas o direito de saber dos gastos e decisões dos governantes. Para a Controladoria Geral da União (CGU), o cidadão bem informado tem mais condições de conhecer outros direitos fundamentais: saúde, educação e benefícios sociais, assim como pode saber quem são os agentes públicos que atuam na máquina administrativa exercendo funções comissionadas e de confiança.

Não obedecer ao disposto na LAI é calar o cidadão. É amputar da cidadania um importante direito que assegura outros direitos. $\mathrm{O}$ caso dos funcionários-fantasmas analisado neste artigo expõe um distanciamento do cidadão e fortalece o poder e o autoritarismo do gestor. $\mathrm{O}$ exercício da democracia está diretamente relacionado à informação e ao conhecimento, sendo que atualmente esses direitos de acesso passam necessariamente pela instrumentação de ferramentas tecnológicas digitais. Se esses itens não estão 
presentes, a cidadania fica prejudicada. A partir de uma decisão judicial, a ALEMA se comprometeu a cumprir a lei, o que já caracteriza, de certa forma, um indício de assumir as responsabilidades da função de poder constituinte do Estado.

\section{Referências}

ALMADA, M. P. A transparência é a bola da vez. Blog Comunicação e Política. Disponível em: < http:// bit.ly/2qkTxnR>. Acesso em: 28 nov. 2016.

BARROS, A. T. BERNARDES, C. B. Comunicação pública e liberdade de informação: condições básicas para mídias legislativas. In: ENCONTRO DA ASSOCIAÇÃO BRASILEIRA DE PESQUISADORES EM COMUNICAÇÃO E POLÍTICA, 4, 2011, Rio de Janeiro. Anais... Rio de Janeiro: Compolítica, 2011. Disponível em: <http://bit.ly/2pQe68d>. Acesso em: 15 maio 2017.

BATISTA, C. L. Informação pública: controle, segredo e direito de acesso. Intexto, Porto Alegre, n.26, p. 204-222, 2012. Disponível em: <http://bit.ly/2rjMBpl>. Acesso em: 18 jan. 2017.

—. Lei de Acesso à Informação: cartilha de orientação ao cidadão.Brasília, DF:Centro de Documentação e Informação, 2011.

BENKLER, Y. The wealth of networks: how social production transforms markets and freedom. New Haven and London: Yale University Press, 2009.

BERTAZZI, D. M. O projeto de lei de acesso à informação e seu impacto sobre os serviços públicos. In: ARTICLE 19. Leis de acesso à informação: dilemas da implantação. 2011. Disponível em: <http:// bit.ly/2qsrLnO>. Acesso em: 4 out 2016.

BRESSER-PEREIRA, L. C. Uma reforma gerencial da administração pública no Brasil. Revista do Serviço Público, Brasília, DF, ano 49, 1, p. 5-42. 1998. Disponível em: <http://bit.ly/2rkiIFE>. Acesso em: jun 2016.

BRITTO, R. R. Sociedade, novas tecnologias de comunicação e a possibilidade de articulação de espaços públicos de debate e embate. In: SOUSA, M. W. (Org.). Recepção midiática e espaço público: novos olhares. São Paulo: p. 34-45, 2010.

CGU - CONTROLADORIA GERAL DA UNIÃO. Acesso à informação pública: uma introdução à Lei 12.527, de 18 de novembro de 2011. Brasília, DF: CGU, 2011

ESCUDERO, R. Comunicação pública: a voz do cidadão na esfera pública - construindo um novo paradigma profissional. Curitiba: Appris, 2015.

FERREIRA, M. K. D. Comunicação pública e cidadania: um estudo exploratório na unidade do Poupatempo Bauru (SP). 182 f. 2009. Dissertação (Mestrado) - Faculdade de Arquitetura, Artes e Comunicação da Universidade Estadual Paulista, Bauru, 2009.

FERREIRA, N. T. Cidadania: uma questão para a educação. Rio de Janeiro: Nova Fronteira, 1993. 
FIGUEIREDO, V. S.; SANTOS, W. J. L. Transparência e controle social na administração pública. São Paulo: Unesp, 2013.

GARCIA, E. L. Falta de transparência facilita a corrupção. Gazeta do Povo, Curitiba, 29 nov 2008. Disponível em: <http://bit.ly/2qon6VF>. Acesso em: 28 nov. 2016.

IBGE -Instituto Brasileiro de Geografia e Estatística. Acesso à internet e posse de telefone móvel celular para uso pessoal. Disponível em:< https://goo.gl/Fj5SPv> Acesso em 12 dez. 2016

LUDKE, M.; ANDRÉ, M. E. D. A. Pesquisa em educação: abordagens qualitativas. São Paulo: EPU, 1986

MARTINS, J; PAIVA, W. Transparência administrativa: publicidade, motivação e participação. São Paulo: Saraiva, 2010.

MATOS, H. Comunicação pública, esfera pública e capital social. In: DUARTE, J. (Org.). Comunicação pública: Estado, mercado, sociedade e interesse público. São Paulo: Atlas, p. 47-57, 2009.

MONTEIRO, G. A singularidade da comunicação pública. In: DUARTE, J. (Org.). Comunicação pública: Estado, mercado, sociedade e interesse público. São Paulo: Atlas: p. 34-46, 2009.

MORAES, A. Direitos humanos fundamentais: teoria geral, comentários aos arts $1^{\circ}$ a $5^{\circ}$ da Constituição da República Federativa do Brasil, doutrina e jurisprudência. 3. ed. São Paulo: Atlas, 2000.

NEIVA, E. Dicionário Houaiss de comunicação e multimídia. São Paulo: Publifolha, 2013.

OLIVEIRA, M. J. C. (Org.). Comunicação pública. Campinas: Alínea, 2004.

PEREIRA, M.; AMARAL, E. COSTA, M. Governo eletrônico e os executivos municipais: o caso de Minas Gerais In: ENCONTRO NACIONAL DA ASSOCIAÇÃO DE PÓS-GRADUAÇÃO E PESQUISA EM CIÊNCIAS SOCIAIS, 34., 2010, Caxambu. Anais ... Caxambu; Anpocs, 2010.

SACRAMENTO, A. R. S.; PINHO, J. A. G. Transparência na administração pública: o que mudou depois da lei de responsabilidade fiscal? Um estudo exploratório em seis municípios da região metropolitana de Salvador. Revista de Contabilidade da UFBA, Salvador, v. 1, n. 1, p. 48-61, 2007.

SILVA, A. C. Evolução da administração pública no Brasil e tendências de novos modelos organizacionais. Cuiabá: ICE.

SILVA, J. A. Curso de direito constitucional positivo. 9 ed. rev. ampl. São Paulo: Malheiros, 1992.

SORJ, B. A nova sociedade brasileira. Rio de Janeiro: Zahar, 2006.

SOUSA, R. M. V. Lei de acesso à informação: um canal à fonte de notícia. São Bernardo do Campo, 2016. Tese (Doutorado em Comunicação Social) - Universidade Metodista de São Paulo, São Bernardo do Campo, 2016.

TABATCHEIK, G. Desvendando os diários secretos: uma análise do uso dos cargos em comissão da Assembleia Legislativa do Paraná (2006-2010). Nep, Curitiba, v. 1, n. 1. 2015. Disponível em: $<$ http://bit.ly/2qodw4P>. Acesso em: 16 de dezembro de 2016.

TORQUATO, G. Tratado de Comunicação Organizacional e Política. São Paulo: Cengage Learning, 2008. YIN, R. K. Estudo de caso: planejamento e método. Porto Alegre: Bookman, 2001.

ZÉMOR, P. La communication publique. Paris: PUF, 1995.

$118 \frac{\text { Comunicação \& Inovação, PPGCOM/USCS }}{\text { v. 18, n. } 37 \text { (103-118) maio-ago } 2017}$ 